\title{
The load of dyspnoea on brain and legs
}

\author{
Andreas von Leupoldt (10) ${ }^{1}$ and Núria Farre (i) $^{2,3}$
}

Affiliations: ${ }^{1}$ Health Psychology, University of Leuven, Leuven, Belgium. ${ }^{2}$ Dept of Cardiology, Hospital del Mar, and Heart Diseases Biomedical Research Group, IMIM (Hospital del Mar Medical Research Institute), Barcelona, Spain. ${ }^{3}$ Dept of Medicine, Universitat Autònoma de Barcelona, Barcelona, Spain.

Correspondence: Andreas von Leupoldt, Health Psychology, University of Leuven, Tiensestraat 102, B-3000 Leuven, Belgium. E-mail: andreas.vonleupoldtakuleuven.be

@ERSpublications

Cognitive impairments are common in patients with dyspnoea, associated with additional adverse health effects, but remain under-recognised and under-treated. Acute dyspnoea can worsen cognitive and locomotor performance, potentiating patient burden. https://bit.ly/3biHnAN

Cite this article as: von Leupoldt A, Farre N. The load of dyspnoea on brain and legs. Eur Respir J 2020; 56: 2001096 [https://doi.org/10.1183/13993003.01096-2020].

Dyspnoea is the subjective experience of breathing discomfort that can vary in quality and intensity and lead to subsequent physiological and behavioural responses [1,2]. It is a highly frightening experience for many patients worldwide and associated with severe disability and impaired functioning. Recurrent acute, as well as chronic, forms of dyspnoea cause significant loss of quality of life and can evolve into an overwhelming burden in all areas of life in affected patients, and also in their caregivers and families [3-5]. Dyspnoea is not only the cardinal symptom in respiratory and heart diseases, such as COPD [6], asthma [7] and heart failure [8], but is also prominent in various other prevalent diseases, including cancer and neuromuscular diseases, as well as mental disorders, such as anxiety, panic and psychosomatic disorders $[2,9-12]$. The enormous relevance of dyspnoea is further reflected by estimations that up to $25 \%$ of the general population and up to $50 \%$ of severely ill patients are suffering from dyspnoea $[2,12]$. Alarmingly, dyspnoea is often under-recognised and under-treated [13], despite the availability of respective diagnostic instruments and multidisciplinary treatment approaches [5, 14-16].

Notably, patients suffering from dyspnoea, for example due to COPD, asthma or heart failure, often present with varying forms of cognitive impairments, ranging from mild intensities to significant dementia [17-19]. For example, across studies the prevalence rates for cognitive impairments often exceed $40 \%$ in COPD patients [17] and vary between $25 \%$ and $75 \%$ in heart failure patients [19]. These impairments are typically attributed to several characteristics of the underlying primary or comorbid diseases, such as hypoxia, hypercapnia, inflammatory processes, impaired (cerebral) blood flow, medications, sleep fragmentation, depression and brain morphological changes [19, 20]. Surprisingly, the impairing effect of dyspnoea itself on cognitive functioning has not received much scientific attention, although it is often (and correctly) argued that dyspnoea is a leading cause for impairments in performance and the ability to function [1, 21, 22]. While this argument has been supported by impressive qualitative research [3, 23], controlled experimental studies examining specific categories of cognitive functioning have long been absent. Only recently, a first set of respective studies became available, suggesting that experimentally induced dyspnoea might indeed impair different domains of cognitive functioning. For example, JURAVLE et al. [24], demonstrated that resistive loaded breathing impairs the neural processing of affective pictures. Moreover, inspiratory threshold loading decreased the performance in a face recognition task and a locomotor task as suggested by VINCKIER et al. [25] and Nierat et al. [26]. Similarly, SuCEC et al. [27, 28] recently demonstrated that resistive load-induced dyspnoea impairs response inhibition and recognition memory [29]. Even the anticipation of upcoming dyspnoea was suggested to affect such cognitive 
processes [30, 31]. However, so far, the potential effects of acute experimental dyspnoea on other important domains of cognitive functioning, including locomotor performance, remain widely unknown.

In this issue of the European Respiratory Journal, LAWI et al. [32] present a study which closes this knowledge gap to a significant extent. In their crossover randomised trial, the authors examined whether acute experimental dyspnoea would interfere with several different cognitive functions in healthy adults. These functions included categorical and phonemic verbal fluency, executive functioning, processing speed and working memory, which were assessed with a battery of validated cognitive tests during breathing through an inspiratory threshold load or during unloaded breathing, respectively. In addition, locomotor performance was tested by a validated timed up and go test (TUG). Their results show dyspnoea-induced impairments across all tests, in particular for participants starting the tests during loaded breathing and subsequently repeating them during the unloaded control condition. This study first demonstrates in the same sample of participants that acute dyspnoea impairs functioning across a whole range of different cognitive domains in addition to locomotor performance. Moreover, it suggests that the relief from dyspnoea as operationalised as a second, unloaded breathing condition might be associated with improvements in cognitive and locomotor functioning. Together, these findings highlight that not only organic and disease-related factors (e.g. hypoxia, hypercapnia, inflammation), but acute dyspnoea per se, can lead to detriment of higher brain functions, which are crucially important in everyday life. In addition, and this is the good news, these impairments might be reversed if dyspnoea is successfully treated.

Of course, as correctly addressed by the authors, this study also has its limitations as inherent to most controlled experimental studies. For example, experimentally induced dyspnoea in safe laboratory environments might only partially mimic the threatening character of real-life dyspnoea. Similarly, cognitive and locomotor functioning in experimental tests might not fully reflect respective performance in more complex real-life situations. Furthermore, the observed dyspnoea-functioning interactions in healthy individuals might not fully mimic the physiological and behavioural responses to acute and chronic dyspnoea in patients suffering this symptom, which requires future replications in diverse patient samples. In this regard it is noteworthy that dyspnoea descriptors, which at least partly reflect different underlying pathophysiological mechanisms, are different in patients with heart failure and with respiratory disease, and also in healthy individuals when dyspnoea is induced by different stimuli [33-35]. Finally, it is worth mentioning that gender also plays a role in dyspnoea perception. Indeed, dyspnoea is more prevalent in women, both in heart failure and respiratory diseases, and women use dyspnoea descriptors that are different than those used by men [36-39]. Whether such differences in gender and dyspnoea descriptors are related to differences in cognitive and locomotor performance remains unknown from the present study and awaits future investigation.

Nevertheless, the present findings by LAwI et al. [32], together with those from previous studies [24-31], have several important implications. First, they highlight that dyspnoea per se changes important higher brain processes, above the level of the brainstem respiratory oscillator required for normal and usually unconscious breathing. Although not directly measured by LAwi et al. [32], several previous studies using different neuroimaging techniques have already demonstrated that experimentally induced dyspnoea activates brain networks, which are also involved in cognitive, affective and motor processing [40-42]. These activations during acute dyspnoea, especially if involving brain areas that are needed for both processing of dyspnoea as well as cognitive and motor functions, limit available brain processing capacities for simultaneous cognitive and locomotor performance $[26,29,30]$. This dyspnoea-cognition/locomotor interference is in line with previous findings on dual-task interference showing that the simultaneous engagement in two tasks diminishes performance in both tasks, especially when depending on shared brain networks $[43,44]$. In addition, this dyspnoea-cognition/locomotor interference is most likely further influenced by other factors, for example negative affect. Dyspnoea as a threatening and highly salient sensation is strongly intertwined with negative affective states and personality traits, such as anxiety and depression, and elicits strong activations in respective affect-related brain networks [40, 41, 45]. This further limits the availability of overall brain capacities for cognitive functioning and locomotor performance. Notably, the mere fearful anticipation as well as observation of dyspnoea and dyspnoea-related stimuli has been shown to impact on higher brain processing [46-50] and to potentially interfere with cognitive processes such as error and picture processing [30, 31].

Moreover, the present study by LAWI et al. [32] calls for more clinical attention towards potential impairments in cognitive and locomotor functions in patients with dyspnoea. Next to the burden due to their primary disease symptoms, these impairments can additionally and substantially interfere with their functioning in daily life, including physical and social activities, job performance, mobility, communication and interpersonal relations, with further potential consequences for patient's families and caregivers [4, 17-19]. Importantly, impaired cognitive and locomotor functioning are associated with significant clinical implications, including worse health status and frequent falls as well as increased risk of 
(longer) hospitalisation and even mortality [17-19, 51, 52]. This can partly be attributed to reduced abilities to adhere to prescribed treatments and less effective self-management, such as forgetting to correctly use the right medication, failure to initiate required behavioural changes (e.g. increases in physical exercise due to fear of falls, balance impairment and dyspnoea itself, dietary changes, smoking cessation) and limited adherence to scheduled clinical appointments [17, 51-53]. It doesn't take much to imagine how difficult it is to adequately perform all these procedures if the necessary cognitive functions and/or brain-leg coordination are impaired. Therefore, diagnostic screenings for these non-organic impairments should find their way into clinical routine assessments of patients with dyspnoea. Whether the hypothesised use of simple respiratory threshold loading together with locomotor gait speed tests such as the TUG might be of diagnostic or predictive value for cognitive impairment in these patients, and even in normally ageing controls [32], is an exciting thought that awaits future validation.

Finally, the results presented by LAwi et al. [32] encourage further examination of whether different available treatment options for dyspnoea as a symptom [54] would also show downstream effects on improving cognitive functioning and locomotor performance. As suggested by the authors, one potential option could be opioids, which have been shown to relieve dyspnoea without changing respiratory mechanics [55]. However, the use of opioids in acute and chronic heart failure has been associated with limited efficacy and frequent side-effects, which currently limits their long-term use in these conditions $[56,57]$. Another option might be physical exercise training, ideally embedded in multidisciplinary treatment/rehabilitation contexts, which, together with improvements in other domains such as muscular, mechanical and psychological functioning, has been demonstrated to alleviate not only dyspnoea, but also cognitive and locomotor function $[16,58]$.

In summary, dyspnoea is still an under-recognised and under-treated major health problem in millions of patients worldwide. It is not only the mere sign of one of the various potentially underlying conditions, but as a threatening and "all-consuming" experience, dyspnoea itself induces additional significant burden to the patient, and their families and caregivers. Acute impairments in several domains of cognitive functioning and locomotion, as demonstrated by LAWI et al. [32], are one important example for this additional burden, which might potentiate ongoing, more chronic forms of cognitive malfunctioning due to the effects of underlying, primary disease processes. Next to the already existing strain due to these diseases, cognitive impairments are associated with additional serious adverse health effects in patients with dyspnoea, but are still not sufficiently recognised. Therefore, it is high time for increased interdisciplinary research and clinical efforts to improve the detection and treatment of cognitive and locomotor impairments in dyspnoeic patients in order to alleviate this additional load of dyspnoea on brain and legs.

Conflict of interest: A. von Leupoldt reports grants from Research Foundation - Flanders (FWO), Belgium (research grants GOA4516N and GOA3718N), Research Foundation - Flanders (FWO) and Research Fund KU Leuven (research infrastructure grant AKUL/19/06; I011320N) and Flemish Government, Belgium (long-term structural research funding Methusalem grant METH/15/011), during the conduct of the study. N. Farre has nothing to disclose.

Support statement: A. von Leupoldt is supported by research grants from the Research Foundation - Flanders (FWO), Belgium (GOA4516N and GOA3718N), by an infrastructure grant from the FWO and the Research Fund KU Leuven, Belgium (AKUL/19/06; I011320N), and by the "Asthenes" long-term structural funding Methusalem grant (METH/15/ 011) by the Flemish Government, Belgium. Funding information for this article has been deposited with the Crossref Funder Registry.

\section{References}

1 Dyspnea. Mechanisms, assessment, and management: a consensus statement. American Thoracic Society. Am J Respir Crit Care Med 1999; 159: 321-340.

2 Parshall MB, Schwartzstein RM, Adams L, et al. An official American Thoracic Society statement: update on the mechanisms, assessment, and management of dyspnea. Am J Respir Crit Care Med 2012; 185: 435-452.

3 Hutchinson A, Barclay-Klingle N, Galvin K, et al. Living with breathlessness: a systematic literature review and qualitative synthesis. Eur Respir J 2018; 51: 1701477.

4 Nakken N, Janssen DJA, van den Bogaart EHA, et al. Informal caregivers of patients with COPD: Home Sweet Home? Eur Respir Rev 2015; 24: 498-504.

5 Booth S, Johnson MJ. Improving the quality of life of people with advanced respiratory disease and severe breathlessness. Breathe (Sheff) 2019; 15: 198-215.

6 Global Initiative for Chronic Obstructive Lung Disease (GOLD) (2020). Global Strategy for Diagnosis, Management, and Prevention of COPD. https://goldcopd.org Date last accessed: 1 April, 2020.

7 Global Initiative for Asthma (GINA) (2020). Global Strategy for Asthma Management and Prevention. https:// ginasthma.org Date last accessed: 1 April, 2020.

8 Pang PS, Cleland JGF, Teerlink JR, et al. A proposal to standardize dyspnoea measurement in clinical trials of acute heart failure syndromes: the need for a uniform approach. Eur Heart J 2008; 29: 816-824.

9 Solano JP, Gomes B, Higginson IJ. A comparison of symptom prevalence in far advanced cancer, AIDS, heart disease, chronic obstructive pulmonary disease and renal disease. J Pain Symptom Manage 2006; 31: 58-69. 
10 American Psychiatric Association. Diagnostic and Statistical Manual of Mental Disorders. 5th Edn. Washington, American Psychiatric Association, 2013.

11 Alpert CM, Smith MA, Hummel SL, et al. Symptom burden in heart failure: assessment, impact on outcomes, and management. Heart Fail Rev 2017; 22: 25-39.

12 Laviolette L, Laveneziana P. ERS Research Seminar Faculty. Dyspnoea: a multidimensional and multidisciplinary approach. Eur Respir J 2014; 43: 1750-1762.

13 Ahmadi Z, Sandberg J, Shannon-Honson A, et al. Is chronic breathlessness less recognised and treated compared with chronic pain? A case-based randomised controlled trial. Eur Respir J 2018; 52: 1800887.

14 Johnson MJ, Fallon M. Chronic breathlessness: time for Cinderella to go to the ball! Eur Respir J 2018; 52: 1801452.

15 Spathis A, Booth S, Moffat C, et al. The Breathing, Thinking, Functioning clinical model: a proposal to facilitate evidence-based breathlessness management in chronic respiratory disease. NPJ Prim Care Respir Med 2017; 27: 27.

16 Spruit MA, Singh SJ, Garvey C, et al. An official American Thoracic Society/European Respiratory Society statement: key concepts and advances in pulmonary rehabilitation. Am J Respir Crit Care Med 2013; 188: e13-e64.

17 van Beers M, Janssen DJA, Gosker HR, et al. Cognitive impairment in chronic obstructive pulmonary disease: disease burden, determinants and possible future interventions. Expert Rev Respir Med 2018; 12: 1061-1074.

18 Irani F, Barbone JM, Beausoleil J, et al. Is asthma associated with cognitive impairments? A meta-analytic review. J Clin Exp Neuropsychol 2017; 39: 965-978.

19 Ampadu J, Morley JE. Heart failure and cognitive dysfunction. Int J Cardiol 2015; 178: 12-23.

20 Dodd JW, Getov SV, Jones PW. Cognitive function in COPD. Eur Respir J 2010; 35: 913-922.

21 Laveneziana P. Qualitative aspects of exertional dyspnea in patients with restrictive lung disease. Multidiscip Respir Med 2010; 5: 211-215

22 Kessler R, Partridge MR, Miravitlles M, et al. Symptom variability in patients with severe COPD: a pan-European cross-sectional study. Eur Respir J 2011; 37: 264-272.

23 Ahmadi NS, Månsson J, Lindblad U, et al. Breathlessness in everyday life from a patient perspective: a qualitative study using diaries. Palliat Support Care 2014; 12: 189-194.

24 Juravle G, Stoeckel MC, Rose M, et al. Investigating the effect of respiratory bodily threat on the processing of emotional pictures. Respir Physiol Neurobiol 2014; 204: 41-49.

25 Vinckier F, Morélot-Panzini C, Similowski T. Dyspnoea modifies the recognition of fearful expressions by healthy humans. Eur Respir J 2018; 51: 1702253.

26 Nierat M-C, Demiri S, Dupuis-Lozeron E, et al. When breathing interferes with cognition: experimental inspiratory loading alters timed up-and-go test in normal humans. PLoS One 2016; 11: e0151625.

27 Sucec J, Herzog M, Van Diest I, et al. The impairing effect of dyspnea on response inhibition. Int J Psychophysiol 2018; 133: 41-49.

28 Sucec J, Herzog M, Van den Bergh O, et al. The effects of repeated dyspnea exposure on response inhibition. Front Physiol 2019; 10: 663.

29 Sucec J, Herzog M, Van den Bergh O, et al. The effect of dyspnea on recognition memory. Int J Psychophysiol 2020; 148: 50-58.

30 Sucec J, Herzog M, Van Diest I, et al. The impact of dyspnea and threat of dyspnea on error processing. Psychophysiology 2019; 56: e13278.

31 Juravle G, Reicherts P, Riechmann-Weinstein M, et al. Neural responses to affective pictures while anticipating and perceiving respiratory threat. Psychophysiology 2017; 54: 182-192.

32 Lawi D, Dupuis-Lozeron E, Berra G, et al. Experimental dyspnoea interferes with locomotion and cognition: a randomised trial. Eur Respir J 2020; 56: 2000054.

33 Simon PM, Schwartzstein RM, Weiss JW, et al. Distinguishable sensations of breathlessness induced in normal volunteers. Am Rev Respir Dis 1989; 140: 1021-1027.

34 Mahler DA, Harver A, Lentine T, et al. Descriptors of breathlessness in cardiorespiratory diseases. Am J Respir Crit Care Med 1996; 154: 1357-1363.

35 Chang AS, Munson J, Gifford AH, et al. Prospective use of descriptors of dyspnea to diagnose common respiratory diseases. Chest 2015; 148: 895-902.

36 Zysman M, Burgel PR, Court-Fortune I, et al. Relationship between gender and survival in a real-life cohort of patients with COPD. Respir Res 2019; 20: 191

37 Ekman I, Boman K, Olofsson M, et al. Gender makes a difference in the description of dyspnoea in patients with chronic heart failure. Eur J Cardiovasc Nurs 2005; 4: 117-121.

38 Gut-Gobert C, Cavaillès A, Dixmier A, et al. Women and COPD: do we need more evidence? Eur Respir Rev 2019; 28: 180055.

39 Skoczyński S, Zejda J, Brożek G, et al. Clinical importance of sex differences in dyspnea and its sex related determinants in asthma and COPD patients. Adv Med Sci 2019; 64: 303-308.

40 Davenport PW, Vovk A. Cortical and subcortical central neural pathways in respiratory sensations. Respir Physiol Neurobiol 2009; 167: 72-86

41 Evans KC. Cortico-limbic circuitry and the airways: insights from functional neuroimaging of respiratory afferents and efferents. Biol Psychol 2010; 84: 13-25.

42 Raux M, Tyvaert L, Ferreira M, et al. Functional magnetic resonance imaging suggests automatization of the cortical response to inspiratory threshold loading in humans. Respir Physiol Neurobiol 2013; 189: 571-580.

43 Li KZH, Bherer L, Mirelman A, et al. Cognitive involvement in balance, gait and dual-tasking in aging: a focused review from a neuroscience of aging perspective. Front Neurol 2018; 9: 913.

44 Pashler H. Dual-task interference in simple tasks: data and theory. Psychol Bull 1994; 116: $220-244$.

45 von Leupoldt A, van den Bergh O, Davenport PW. Anxiety, depression and panic. In: Mahler DA, O’Donnell DE, eds. Dyspnea: Mechanisms, Measurement and Management. 3rd Edn. Boca Raton, CRC Press, 2014; pp. 129-143.

46 Stoeckel MC, Esser RW, Gamer M, et al. Brain responses during the anticipation of dyspnea. Neural Plast 2016; 2016: 6434987 .

47 Esser RW, Stoeckel MC, Kirsten A, et al. Brain activation during perception and anticipation of dyspnea in chronic obstructive pulmonary disease. Front Physiol 2017; 8: 617. 
48 Faull OK, Jenkinson M, Ezra $M$, et al. Conditioned respiratory threat in the subdivisions of the human periaqueductal gray. eLife 2016; 5: e12047.

49 Herigstad M, Faull OK, Hayen A, et al. Treating breathlessness via the brain: changes in brain activity over a course of pulmonary rehabilitation. Eur Respir J 2017; 50: 1701029.

50 Herzog M, Sucec J, Van Diest I, et al. Observing dyspnoea in others elicits dyspnoea, negative affect and brain responses. Eur Respir J 2018; 51: 1702682.

51 Oliveira CC, Lee AL, McGinley J, et al. Balance and falls in acute exacerbation of chronic obstructive pulmonary disease: a prospective study. COPD J Chronic Obstr Pulm Dis 2017; 14: 518-525.

52 Lee K, Pressler SJ, Titler M. Falls in patients with heart failure. J Cardiovasc Nurs 2016; 31: 555-561.

53 Alosco ML, Spitznagel MB, van Dulmen M, et al. Cognitive function and treatment adherence in older adults with heart failure. Psychosom Med 2012; 74: 965-973.

54 Johnson MJ, Yorke J, Hansen-Flaschen J, et al. Towards an expert consensus to delineate a clinical syndrome of chronic breathlessness. Eur Respir J 2017; 49: 1602277.

55 Ekström M, Nilsson F, Abernethy AA, et al. Effects of opioids on breathlessness and exercise capacity in chronic obstructive pulmonary disease. A systematic review. Ann Am Thorac Soc 2015; 12: 1079-1092.

56 Gil V, Domínguez-Rodríguez A, Masip J, et al. Morphine use in the treatment of acute cardiogenic pulmonary edema and its effects on patient outcome: a systematic review. Curr Heart Fail Rep 2019; 16: 81-88.

57 Johnson MJ, Cockayne S, Currow DC, et al. Oral modified release morphine for breathlessness in chronic heart failure: a randomized placebo-controlled trial. ESC Heart Fail 2019; 6: 1149-1160.

58 Langlois $\mathrm{F}, \mathrm{Vu}$ TTM, Chassé $\mathrm{K}$, et al. Benefits of physical exercise training on cognition and quality of life in frail older adults. J Gerontol B Psychol Sci Soc Sci 2013; 68: 400-404. 